\title{
Attention demands during reading and the occurrence of brief (express) fixations
}

\author{
ALBRECHT WERNER INHOFF and RICHARD TOPOLSKI \\ State University of New York, Binghamton, New York \\ and \\ FRANÇOISE VITU and J. KEVIN O'REGAN \\ CRNS, EPHE, EHESS, University René Descartes, Paris, France
}

\begin{abstract}
Eye movements were recorded while subjects read passages of text repeatedly (Experiment 1) and while normal text and strings of homogeneous letters were fixated (Experiment 2). Text repetition decreased fixation durations and increased saccade size, presumably because it decreased attention demands. Irrespective of repetition, however, no distinct distribution of brief (express) fixations emerged. In Experiment 2, fixation durations were shorter and saccades were larger when strings of homogeneous letters were "read," indicating that this condition decreased attention demands. Again, however, no distinct distribution of express fixations emerged. These findings pose problems for the view that attentional processes determine the occurrence of brief (express) fixation durations in reading. Supplementary analyses of Experiments 1 and 2 suggested that visuospatial processing affected fixation durations, irrespective of linguistic processing demands.
\end{abstract}

In overlap and gap tasks, subjects fixate a central location and move the eyes laterally in response to the presentation of a peripheral target. In a typical overlap trial, subjects fixate (attend) a centrally presented visual stimulus while a to-be-fixated peripheral target appears, so that fixated and peripherally available stimuli are concurrently available. In a typical gap trial, the fixated (attended) stimulus is erased prior to target presentation, creating a "gap" between the availability of fixated and to-be-fixated stimuli.

Examination of fixation duration distributions on gap trials often reveals a distinct distribution of (express) saccades with latencies between 80 and $130 \mathrm{msec}$ and a mode of approximately $120 \mathrm{msec}$, at least in some subjects, and additional modes for longer duration latencies. No distinct express saccade peak is obtained in overlap trials (Boch \& Fischer, 1986; Fendrich, Hughes, \& Reuter-Lorenz, 1991; Fischer, 1986, 1987, 1989, 1993; Fischer \& Weber, 1988; Kalesnykas \& Hallett, 1987; Reuter-Lorenz, Hughes, \& Fendrich, 1991; Weber \& Fischer, 1990).

It is unlikely that express saccades are the result of either more effective visual target processing on gap trials or a higher visual distinctiveness of target stimuli. Gap effects combine additively with visual target characteristics (Reuter-Lorenz et al., 1991) and express saccades occur

The research reported in this article was supported by National Science Foundation Grant BNS-9010067 and by the Center for Cognitive and Psycholinguistic Studies at SUNY-Binghamton. Françoise Vitu was supported by a grant from the French government's Ministère des Affaires Etrangers while she had a postdoctoral position at SUNYBinghamton. Requests for reprints should be sent to A. Inhoff, Department of Psychology, SUNY-Center, Binghamton, NY 13902-6000. on gap trials, even when targets are presented in a nonvisual modality (Fendrich et al., 1991). It is also unlikely that all express saccades are anticipatory movements, as they are present on gap trials even when anticipatory saccades are removed (Kalesnykas \& Hallett, 1987). However, anticipations may inflate the frequency of express saccades. Jutner and Wolf (1992) showed that the proportion of express saccades is a function of the number of catch trials, with fewer express saccades when the proportion of catch trials is high (see also Vitu, 1993).

Other findings suggest that the occurrence of express saccades is related to attentional processes (Braun \& Breitmeyer, 1988, 1990; Fischer, 1987, 1993; Fischer \& Breitmeyer, 1987; Mayfrank, Mobashery, Kimming, \& Fischer, 1986). For instance, in Braun and Breitmeyer's (1990, Experiment 3) study, gap and overlap conditions were defined with reference to the attended, rather than the fixated, stimulus. Subjects fixated a continuously visible central marker while a to-be-attended stimulus was shown to the right or left of fixation. Two hundred milliseconds prior to target onset, the attended stimulus was extinguished for a variable duration, ranging from $0 \mathrm{msec}$ (no extinction, creating an overlap condition) to more than $600 \mathrm{msec}$ (creating different gap conditions), with attended and target stimuli occupying opposite visual fields. Confirming earlier findings, no express saccades occurred in the 0-msec (overlap) extinction condition. However, when the attended stimulus was extinguished $200 \mathrm{msec}$ prior to target onset, more than $50 \%$ of all responses constituted express saccades, irrespective of extinction duration.

Fischer and Weber (1993) provided a comprehensive review of the attention hypothesis. According to their view, attentional processes prior to, during, and after tar- 
get presentation control the occurrence of express saccades. Target localization and saccade programming are assumed to be relatively fast so that saccades are generally ready for movement execution within 80 to $130 \mathrm{msec}$. However, when attention is engaged, saccade programming is inhibited until it has been disengaged. In gap trials, offset of the attended stimulus can be used as a cue to disengage attention prior to target presentation. When this occurs, the latency of some saccades is determined solely by oculomotor movement programming demands, yielding a distinct distribution of express saccades. In overlap trials, attention remains engaged until the target occurs; subsequent disengagement of attention requires time, hence the lack of express saccades. The occurrence of distinct distributions of saccade latencies, consisting of express saccades and longer latency saccades, thus suggests the availability of at least two distinct types of oculomotor control, with one type of eye movement occurring when attention is engaged prior to target presentation and the other type occurring when attention is disengaged.

In recent work on oculomotor control, which measured fixation durations during the reading of text, distinct types of oculomotor control were also identified. Morrison's (1984) results were crucial in establishing this distinction. In that study, subjects read text while eye movements were recorded. In one condition, a visual mask replaced fixated text for a variable duration at fixation onset. The results showed effects of mask application on the occurrence of fixations of $150 \mathrm{msec}$ or more. In general, the proportion of fixations between 150 and 300 msec decreased and the proportion of longer fixation durations increased when visual masks were applied. In contrast, the occurrence of brief fixations of less than $150 \mathrm{msec}$ was unaffected by mask application. Even though the distribution of fixation duration in reading tasks is generally unimodal, readers thus appear to use two distinct classes of fixations, with one class being sensitive to on-line perceptual and cognitive processing demands and another class being insensitive to these demands (Inhoff, Topolski, \& Wang, 1992; McConkie, Underwood, Zola, \& Wolverton, 1985; Morrison, 1984; O'Regan, 1993).

According to Fischer (1993; Fischer \& Weber, 1990, 1993), the attention hypothesis is sufficiently general to account for variations in oculomotor activity in a variety of tasks, including reading. Consistent with this view, the hypothesis could accommodate Morrison's (1984) findings by assuming that attention was engaged during fixations of $150 \mathrm{msec}$ and more; hence, inhibitory effects of visual masking occurred during reading for this class of fixations. Conversely, attention may not have been engaged during shorter duration fixations; hence, the masking of segments of text at fixation onset was ineffective for this distinct class of brief fixations. Furthermore, it is plausible to assume that brief fixations of $150 \mathrm{msec}$ or less occur relatively rarely in complex tasks such as reading, as attention may be required to ensure successful word identification (Becker, 1976) and text comprehension (Inhoff, 1984). Consequently, brief fixation durations during reading may not form a distinct distribution.
The major goal of the present study was to determine whether Fischer's (1993; Fischer \& Weber, 1993) attention hypothesis, as it emerged from gap and overlap studies, can contribute to the understanding of oculomotor control during reading. Two experiments that systematically varied attention demands were conducted. According to Fischer's attention hypothesis, the occurrence of brief fixations should increase as attention demands decrease. Furthermore, a distinct distribution of brief fixations of $150 \mathrm{msec}$ or less may emerge when attention demands during reading are negligible.

\section{EXPERIMENT 1 Effects of Text Repetition}

In Experiment 1, subjects read passages of text several times, thereby reducing attention dedicated to semantic, syntactic, lexical, and sublexical processes. Rereadings should result in a general decrease of fixation durations (Hyona \& Niemi, 1990). More important, engagement of attention should decrease with repetition and readers' eye movements should increasingly rely on mere detection of a to-be-fixated target, saccade planning, and saccade execution, resulting in the gradual emergence of a distinct distribution of brief (express) fixations.

\section{Method}

Subjects. Ten undergraduate students at the State University of New York at Binghamton were paid to participate in the experiment. All the students could read without corrective lenses and classified themselves as good readers.

Materials. Five passages of text that covered a single theme, such as the spread of AIDS or U.S. arms policies, were obtained from national news magazines. All passages contained between 89 and 97 words, with a mean word length of 4.8 character spaces. In each passage, the text extended across 10 lines, with each line containing between 6 and 13 words (a maximum of 65 character spaces per line, including blanks). Passage order was held constant across the five passage readings.

Apparatus. The subjects were tested in a sound-insulated, dimly illuminated room. A $60-\mathrm{Hz}$ noninterlaced VGA monitor with .28$\mathrm{mm}$ dot pitch was used to display text that was shown in light green on a black background. The brightness of the room and of the character display were occasionally adjusted within and between subjects to minimize track losses, but all brightness levels were kept within the luminance levels that yielded express saccades in prior studies. Text was shown in high-resolution $640 \times 480$ VGA display mode that generated crisp Word Perfect character images. The distance between the readers' eyes and the monitor was set at $70 \mathrm{~cm}$; at this viewing distance, each letter of text subtended $.33^{\circ}$ of visual angle.

Eye movements were recorded via a fifth-generation dual Purkinje SRI eye-tracking system. Viewing was binocular, but eye movements were recorded from the right eye only. The system has a visual resolution of $10^{\prime}$ of arc and its output is linear over the vertical and horizontal ranges of the VGA display. Analog input from the eye tracker was digitized via a Data Translation A/D converter housed in a Dell 310 computer. The computer controlled the visual display and recorded and stored horizontal and vertical coordinates of the reader's eye position every $5 \mathrm{msec}$. One subject's eye position was sampled every $2 \mathrm{msec}$, after a software upgrade had been implemented. The continuous eye-location record was used to determine fixation durations and saccade size. A Logitech mouse was also interfaced with the computer and served as a buttonpush panel that controlled the onset and offset of lines of text. 
Procedure. The subjects were tested individually. When a subject arrived in the laboratory, a bite bar that served to reduce head movements during the experiment was prepared. The experiment began with a two-dimensional calibration of the eye-tracking system. During calibration, the subject was requested to fixate four monitor positions (left top, right top, left bottom, right bottom) as they sequentially appeared on the screen, and to manually depress a mouse key when the indicated location was accurately fixated. Mouse pressing resulted in the sampling of horizontal and vertical fixation location values for $150 \mathrm{msec}$. These $x / y$ values were then mapped onto the corresponding CRT locations. After calibration was completed, six character-size areas were illuminated (top left, top right, bottom left, bottom right, $5 \mathrm{~cm}$ to the right of the center and $5 \mathrm{~cm}$ to the left of the center) and the subject was asked to fixate each of the illuminated locations. During this calibration check phase, the subject's eye position was plotted on the screen so that it appeared as a yellow one-character grid cursor that moved in synchrony with the eyes. The subjects were reminded that the task was not to superimpose the grid cursor on the illuminated character position, but to look at the illuminated character position so that the magnitude of the calibration error could be determined. The calibration was considered successful when the subject's computergenerated eye position (the yellow cursor) deviated by no more than one character space from the actual eye position (the illuminated character spaces).

After successful calibration, the subject was asked to fixate a onecharacter-sized marker at the left side of the screen and to depress the Logitech mouse to display a line of text. Mouse pressing erased the fixation marker and displayed a line of text. The first letter of each line of text was shown five character spaces to the right of the fixated marker. Reading for meaning was encouraged. The second pressing of the mouse, after line reading had been completed, erased the text display and triggered the presentation of the leftside fixation marker for a quick calibration check. This calibration check followed each line reading to maintain tracking accuracy throughout the experiment. Another pressing of a mouse button, after the calibration check was completed, led to the display of the following line of text, again with the first character of text occurring to the right of the fixation marker. All passages of text were read in this line-by-line presentation mode. After passage reading was completed, the subject was asked to provide a short summary of the passage (first reading only). The subjects read two sample passages prior to the onset of the experiment to become familiarized with the equipment and procedure.

Data analyses and design. The continuous record of fixation locations was used to determine fixations of $50 \mathrm{msec}$ or more, ${ }^{1}$ yielding a total of 13,892 fixations (corresponding to .60 fixation per word). Several types of fixations were excluded from this pool. First, all fixations on line-initial and line-ending words were deleted, as fixations on these words were either not preceded or not followed by a fixation of text. We also excluded the first fixation on a line of text when it occupied a word following the line-initial word. Second, we excluded fixations that followed regressions and all forward fixations that occupied previously fixated text, as occurred, for instance, when several small forward fixations followed a large regression. Third, we excluded fixations that followed momentary track losses and extremely large saccades of 20 or more character spaces. Finally, we excluded fixations that followed one-character saccades. ${ }^{2}$ This yielded a total of 8,891 eligible saccade-fixation pairs.

Following Fischer's (e.g., 1986) work, frequency distributions were of primary interest. These distributions were determined for fixation durations and saccade size as a function of text repetition. Effects of repetition were also analyzed via single-factor analyses of variance (ANOVAs).

\section{Results and Discussion}

The number of eligible saccade-fixation pairs systematically decreased across readings. Across subjects, 2,308, $1,999,1,774,1,410$, and 1,400 pairs were obtained from the first to fifth passage reading, respectively. Examination of fixation durations and saccade size, as shown in Table 1, confirmed powerful effects of repetition. ${ }^{3}$ Fixation durations decreased by approximately $24 \mathrm{msec}$ from the first to the fifth reading $[F(4,36)=9.79, p<.001]$, and saccade size increased from 8.6 character spaces during the first reading, to 11.7 spaces during the fifth reading $[F(4,36)=30.96, p<.001]$. These powerful effects of repetition confirm and extend earlier findings (Hyona \& Niemi, 1990).

The distribution of fixation durations and saccade sizes. The distribution of fixation durations as a function of repetition, shown in Figure 1, was of primary interest. According to the attention hypothesis, changes in attention engagement may affect the prevalence of short-duration fixations. Specifically, the frequency of brief fixations should increase as foveal and parafoveal attention demands decrease with repetition.

As can be seen in Figure 1, the results of Experiment 1 provide little, if any, support for this prediction. The pattern of brief fixations was nearly identical across all five passage readings and the overall effect of repetition on the frequency of brief fixations was quite small. Specifically, the percentage of brief fixations of $150 \mathrm{msec}$ or less amounted to $9.5 \%, 10 \%, 12.5 \%, 13.2 \%$, and $12.5 \%$ during the first to fifth passage readings, respectively.

The distribution of saccade sizes was also examined to determine whether repeated text readings lead to unusual oculomotor strategies. As can be seen in Figure 2, the powerful effect of repetition consisted of a general shift toward larger saccades, indicating that a relatively normal pattern of oculomotor activity was used during all text readings.

Supplementary regression analyses. The fixation duration data are difficult to reconcile with the attention hypothesis. However, this difficulty rests on the assumption that repeated text reading gradually extinguished-or substantially decreased-attention demands, so that the engagement and disengagement of attention prior to fixation

Table 1

Means $(M)$ and Standard Deviations (SD) for Forward Fixation Duration (in Milliseconds) and Saccade Size (Character Space Units) as a Function of Repetition

\begin{tabular}{lccccc} 
& \multicolumn{2}{c}{ Fixation } & Duration & & \multicolumn{2}{c}{ Saccade Size } \\
\cline { 5 - 6 } \cline { 5 - 6 } Readings & $M$ & $S D$ & & $M$ & $S D$ \\
\hline First & 224 & 28.7 & & 8.6 & 1.2 \\
Second & 215 & 29.5 & & 9.5 & 1.3 \\
Third & 206 & 26.0 & 10.2 & 1.3 \\
Fourth & 203 & 26.0 & 10.9 & 1.3 \\
Fifth & 200 & 28.1 & 11.7 & 1.5 \\
\hline
\end{tabular}




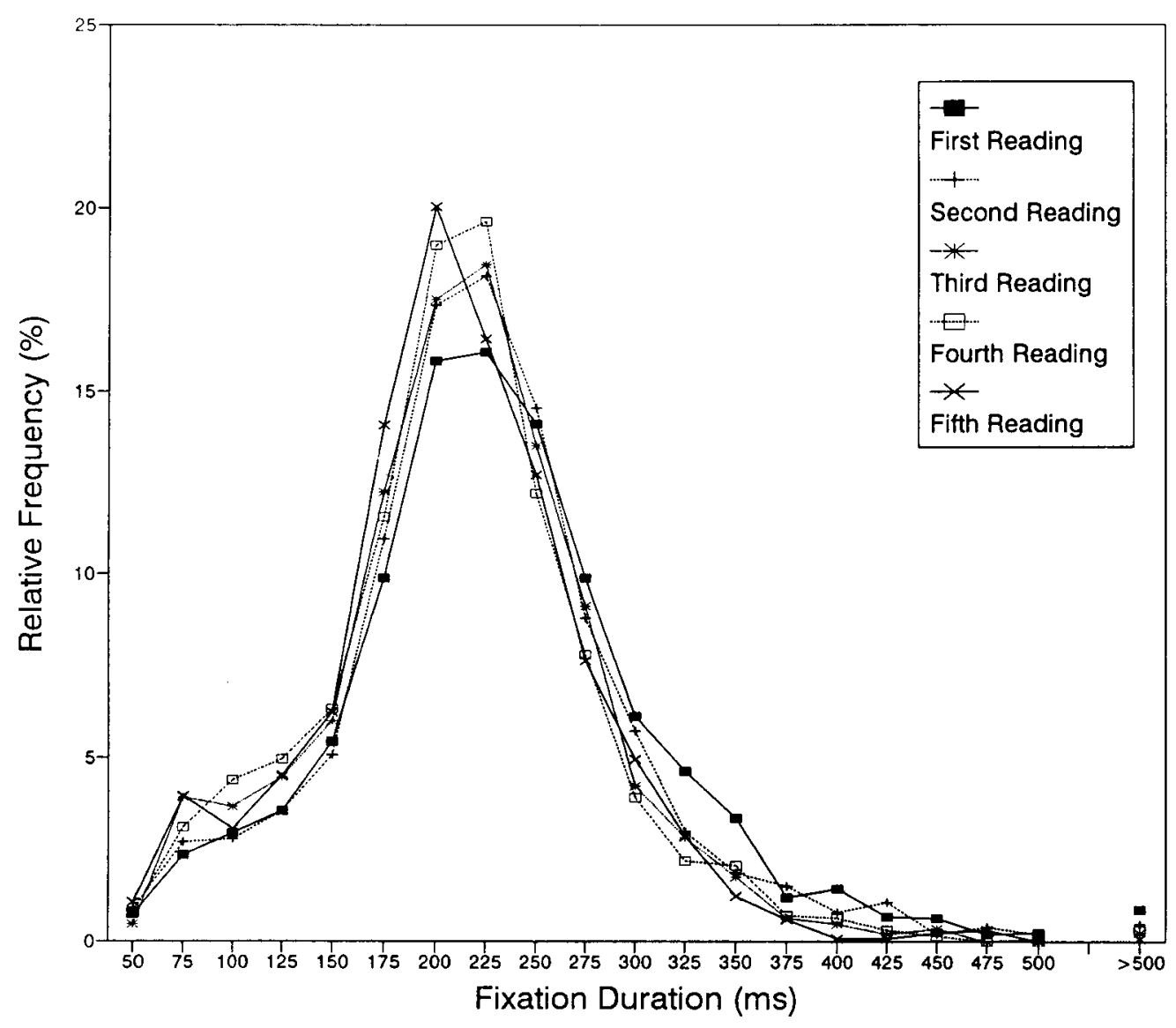

Figure 1. The distribution of fixation durations as a function of repetition. The values show the proportion of fixations in relation to the total number of fixations per reading condition.

onset differed substantially during the first and fifth passage readings. To examine the validity of this assumption, linear regression analyses were computed, using fixation durations during the first and fifth readings as criterion variable.

Two predictor variables were used to assess attention demands. One predictor, the frequency per million words of a word's occurrence in print (Kučera \& Francis, 1967), was assumed to measure demands of cognitive/linguistic processes. Effects of word frequency on eye movements during reading have been demonstrated in a number of earlier studies (e.g., Inhoff, 1984; Inhoff \& Rayner, 1986; Just \& Carpenter, 1980; Rayner \& Duffy, 1986). If rereading decreased processing demands, then effects of word frequency, which should be present during the first reading, may no longer be present during the fifth reading. A second predictor, the size of a saccade to a parafoveally available word, was assumed to be sensitive to perceptual analyses of text. Small saccades are generally followed by shorter fixation durations than are large saccades (Inhoff \& Rayner, 1986; Pollatsek, Rayner, \& Balota, 1986), presumably because they move the eyes to text locations that were close to high-acuity vision during the prior fixation. After several rereadings, effects of saccade size on the following fixation duration may cease to exist, since the ease of perceptual analyses should increase. Following Lorch and Myers's (1990) recommendation, each of the two analyses consisted of two steps. For each subject, we entered the two predictors simultaneously to obtain the corresponding regression coefficients. This was followed by a single-group $t$ test, which was applied to each of the two sets of coefficients.

The analyses of the first passage reading revealed the anticipated effects of word frequency $[t(9)=3.00, S E=$ $.02, p<.05]$ and saccade size $[t(9)=2.61, S E=.05$, $p<.05]$. Fixation durations increased after large saccades and when low-frequency words were fixated. The effect of saccade size on fixation durations was also evident during the fifth passage reading $[t(9)=2.34, S E=$ $.06, p<.05]$, but the effect of word frequency was no longer significant $[\mathrm{t}(9)=1.12, S E=.03]$. Consequently, repetition of text extinguished attention dedicated to lexical analyses. However, it did not eliminate the effects of perceptual analyses. 


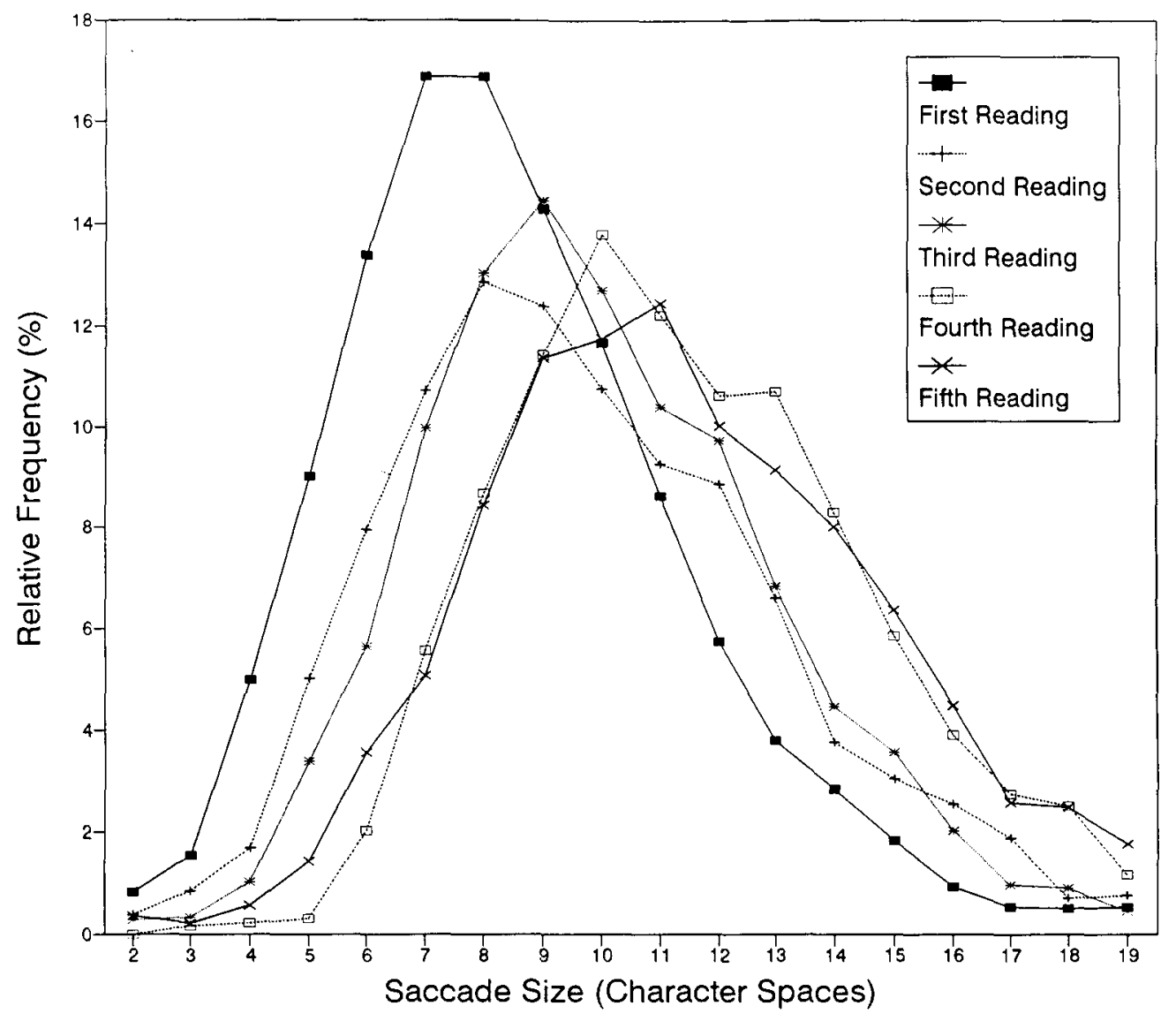

Figure 2. The distribution of saccade size as a function of repetition.

\section{EXPERIMENT $2^{4}$}

The results of Experiment 1 suggest that perceptual analyses of fixated text cannot be extinguished via repeated text readings. To create reading conditions that may effectively eliminate these analyses, subjects in Experiment 2 "read" strings of homogeneous characters ( $\mathrm{z}$ text) as quickly as possible. $\mathrm{Z}$ text was constructed by replacing all letters of text with the letter $z$; for instance, the expression "The ancient city of ..." would be presented as " Zzz zzzzzzz zzzz zz ...." Letters were continuously repeated, so the reading of $\mathrm{z}$ text should not impose demands on perceptual analyses. $Z$ text should thus lead to a sequence of fixations that are not subject to the engagement and disengagement of attention and should yield a distinct distribution of brief (express) fixations.

The reading of standard text was used as an experimental control condition. No distinct distribution of brief fixations was expected in this condition. Two additional control conditions were included. In these conditions, subjects were asked to detect a specific target letter $(c)$ in normal text and in modified $\mathrm{z}$ text in which all letters of text were replaced with the letter $z$, except for the letter $c$. For in- stance, the expression "The ancient city of ..." would be presented as ' Zzz zzczzzz czzz zz ...." Letter detection was assumed to engage attention irrespective of text type and thus yield a distinct distribution of brief fixations neither in the normal text condition nor in the modified $\mathrm{z}$-text condition.

\section{Method}

Subjects. Sixteen undergraduate psychology students at the State University of New York at Binghamton participated for course credit. All the subjects fulfilled the following criteria: They had uncorrected normal vision, were native speakers of English, rated themselves as fluent readers, and were naive with respect to the purpose of the experiment. None of the subjects had participated in Experiment 1.

Apparatus. A 60-Hz SONY-multisync EGA color monitor with a $640 \times 240$ resolution was used to display text in light green on a black background. The EGA mode generated somewhat poorer letter outlines than the VGA mode used in Experiment 1. The distance between the readers' eyes and the monitor was set at $65 \mathrm{~cm}$; at this viewing distance, each letter of text subtended $.33^{\circ}$ of visual angle.

The hardware setup of Experiment 2 was largely identical to the setup used in Experiment 1, except for some minor differences. Instead of a Logitech mouse, a double pull/double push spring button was used by the subject to control the onset and offset of text, and 
a Metrabyte clock was used to measure fixation durations to the nearest $1 \mathrm{msec}$. Calibration was checked via the sequential fixation of eight character-size boxes that formed an octagon around the screen's center.

Materials. A master list of passages was constructed, which contained the 5 passages of text used in Experiment 1 plus 11 similar passages that were obtained from national news magazines. All the passages contained between 75 and 97 words and covered a single theme.

Each passage from the master list was used to derive two additional types of " passages." One additional type consisted of $z$ text, which was obtained by replacing all letters of a passage of text with the letter $z$, and one consisted of modified $z$ text, which was obtained by replacing all letters of a passage with the letter $z$, except for the letter $c$. The three versions of each passage, standard text and the two types of $\mathrm{z}$ text, were thus matched on string lengths, the sequential ordering of string lengths, and the number of letter string units per line, but differed radically in the availability of letterlevel, lexical-level, and contextual-level information.

Four experimental lists were constructed, each containing 16 passages, half of which consisted of standard text. Of the remaining passages, 4 were $z$ text and 4 were modified $z$ text. Each experimental list used the same passage ordering as the master list, except that half of the passages of each experimental list consisted of the two types of $z$ text. Specifically, standard text consisted of Passages 1-4 and 9-12 (List 1), 1-8 (List 2), 9-16 (List 3), and 5-8 plus 13-16 (List 4). Z text consisted of Passages 5-8 (List 1), 9-12 (List 2), 1-4 (List 3), and 13-16 (List 4). The remaining blocks of passages on each experimental list were composed of modified $z$ text.

Design. On each of the four experimental lists of passages, one four-passage block of standard text was used in the normal reading condition and one was used in the reading-plus-letter-detection condition. The four-passage blocks of $\mathrm{z}$ text and modified $\mathrm{z}$ text were used in the $z$-reading and $z$-detection conditions, respectively. Passage type was counterbalanced across lists so that each passage (including its derivatives) was read in all four experimental conditions. Each subject read one list of passages, with list order counterbalanced across 4 successive subjects.

Procedure. The subjects were asked to read standard text for meaning in the reading condition. After approximately every second passage reading, they were asked to provide a summary of the most recently read passage. All the subjects provided accurate summaries. Intersubject differences in the recall of passage details were evident but not evaluated, as they were not considered critical for the purpose of the study. During the reading of $z$ text, the subjects were instructed to move their eyes as fluently as possible along lines of print. They were informed that this condition was used to obtain baseline oculomotor latencies; for that purpose, the subjects were encouraged to fixate several of the letter strings on each line. No questions followed $z$-text readings.

Experiment 2 also included two letter-detection control conditions. In a reading-plus-letter-detection condition, the subjects were informed that the reading of a passage of standard text could be followed by a comprehension question and a query concerning the number of $c s$ in the passage. When modified $z$ text was read, they were informed that passage reading might be followed by a query concerning $c$ frequencies. The subjects were asked to provide their best guess when they were unsure about the exact number of target letters. Again, they provided accurate passage summaries in the reading-plus-letter-detection condition. Furthermore, none of the subjects reported more $c s$ than were actually present or missed more than $20 \%$ of the $c \mathrm{~s}$, indicating that the letter-detection instruction was effective. However, since the subjects reported the total number of target letter occurrences, we could not determine whether a particular letter was detected or when successful letter detection occurred. All passages were shown in five successive two-line displays. This was based on the assumption that presentation of larger text segments might favor the occurrence of brief fixations.

Prior to the experiment, the subjects read four sample passages, each illustrating one of the four experimental conditions. They were thus familiar with each of the four experimental tasks before the experimental list of passages was read. This was followed by the reading of one of the four experimental lists of passages. No additional practice passages were used during the experimental list reading. Instead, the subjects were informed about the to-be-executed task prior to the onset of the corresponding block of four passages.

Data analyses and design. The criteria were the same as those applied in Experiment 1. Again, the distribution of fixation durations, as a function of reading conditions, was of primary interest.

\section{Results and Discussion}

A total of 14,087 fixation-saccade pairs were available: 3,570 pairs in the standard text/reading condition, 4,604 pairs in the standard text/reading-plus-letter-detection condition, 2,439 pairs in the $\mathrm{z}$-text/reading ( $\mathrm{z}$-reading) condition, and 3,474 pairs in the modified $z$-text/detection (z-detection) condition. Table 2 shows fixation durations and saccade size in the four task conditions.

Paired comparisons revealed fixation durations that were 19 msec shorter when $\mathrm{z}$ text was read than when normal text was read $[t(15)=2.30, S E=8.0, p<.05]$. The two letter-detection conditions showed smaller effects of text type, with fixations that were $9 \mathrm{msec}$ longer when standard text was read and searched for $c$ occurrences than when modified $\mathrm{z}$ text was searched for $c$ occurrences. This difference was not significant $[t(15)=1.17, S E=7.7$, $p>.25]$. Letter detection required fixation durations that were $30 \mathrm{msec}$ longer than did reading; the letter-detection effect was significant for standard text $[t(15)=4.49$, $S E=5.7, p<.01]$ and for the two types of $\mathrm{z}$ text $[t(15)$ $=3.09, S E=11.5, p<.01]$.

Examinations of saccade size revealed similar effects. When $\mathrm{z}$ text was read, saccades were 1.7 character spaces larger than when normal text was read $[t(15)=5.75$, $S E=.3, p<.001]$. A similar effect of text type was evident in the two letter-detection conditions, with larger saccades for modified $\mathrm{z}$ text $[t(15)=4.99, S E=.3, p<$ $.001]$. Letter detection also required shorter saccades than reading; the letter-detection effect was significant for standard text $[t(15)=4.65, S E=.2, p<.01]$ and for the two types of $\mathrm{z}$ text $[t(15)=4.30, S E=.3, p<.01]$.

Saccades and fixation durations thus converge in showing that $z$ text imposed fewer processing demands than

Table 2

Means $(M)$ and Standard Deviations (SD) for Fixation Duration and Saccade Size as a Function of Text and Task Type

\begin{tabular}{lcccccc} 
& \multicolumn{2}{c}{ Fixation } & Duration & & \multicolumn{2}{c}{ Saccade Size } \\
\cline { 6 - 7 } \cline { 5 - 6 } \multicolumn{1}{c}{ Condition } & $M$ & $S D$ & & $M$ & $S D$ \\
\hline Standard text/reading & 283 & 40.8 & & 8.4 & .96 \\
Standard text/reading & 309 & 49.2 & & 7.6 & .99 \\
$\quad$ and detection & & & & & \\
$Z$ Z text/reading & 264 & 37.2 & & 10.1 & 1.5 \\
Modified z text/detection & 300 & 70.1 & & 8.9 & 1.5 \\
\hline
\end{tabular}


standard text in the reading conditions. A similar tendency, though less robust, emerged in the letter-detection conditions.

The distribution of fixation durations and saccade sizes. The shape of the distribution of fixation durations was of primary theoretical interest. According to the attention hypothesis, the "reading" of $\mathrm{z}$ text should produce the largest proportion of short-duration fixations with a distinct mode for brief fixations, as readers may not need to engage attention in this condition. The results, shown in Figure 3, fail to confirm this prediction. All four conditions showed unimodal distributions and there was virtual overlap in the four distributions when fixations between 50 and $175 \mathrm{msec}$ were considered. In the reading conditions, text type primarily affected the distribution of longer duration fixations, with a preponderance of fixations between 175 and $275 \mathrm{msec}$ in the z-text condition and a preponderance of longer fixation durations in the standard text condition.

Examination of the fixation durations for each individual reader further indicated that distinct peaks of brief fixations for some of the subjects were not obscured in the overall analysis. Figure 4 shows the distribution of fixation durations for both the reader with the shortest and the reader with the longest mean fixation durations. As can be seen, neither subject showed a bimodal distribution.

Again, the distribution of saccade sizes was examined for abnormalities in oculomotor activity (see Figure 5). All four conditions showed normal oculomotor activity, expressed in unimodal saccade size distributions. The largest saccades occurred in the z-text/reading condition, supporting the view that this condition imposed relatively few processing demands.

Supplementary regression analysis. Z-text reading did not require letter discrimination, word identification, or comprehension of text. To accommodate the lack of brief fixations under these conditions, the attention hypothesis must assume that variations of fixation durations in this condition were associated with some processing demands.

Following the supplementary analyses of Experiment 1, we determined whether fixation durations were affected by the size of the preceding saccade. Visuospatial processing of fixated text may be obligatory and may be more demanding after large saccades, even when homogeneous

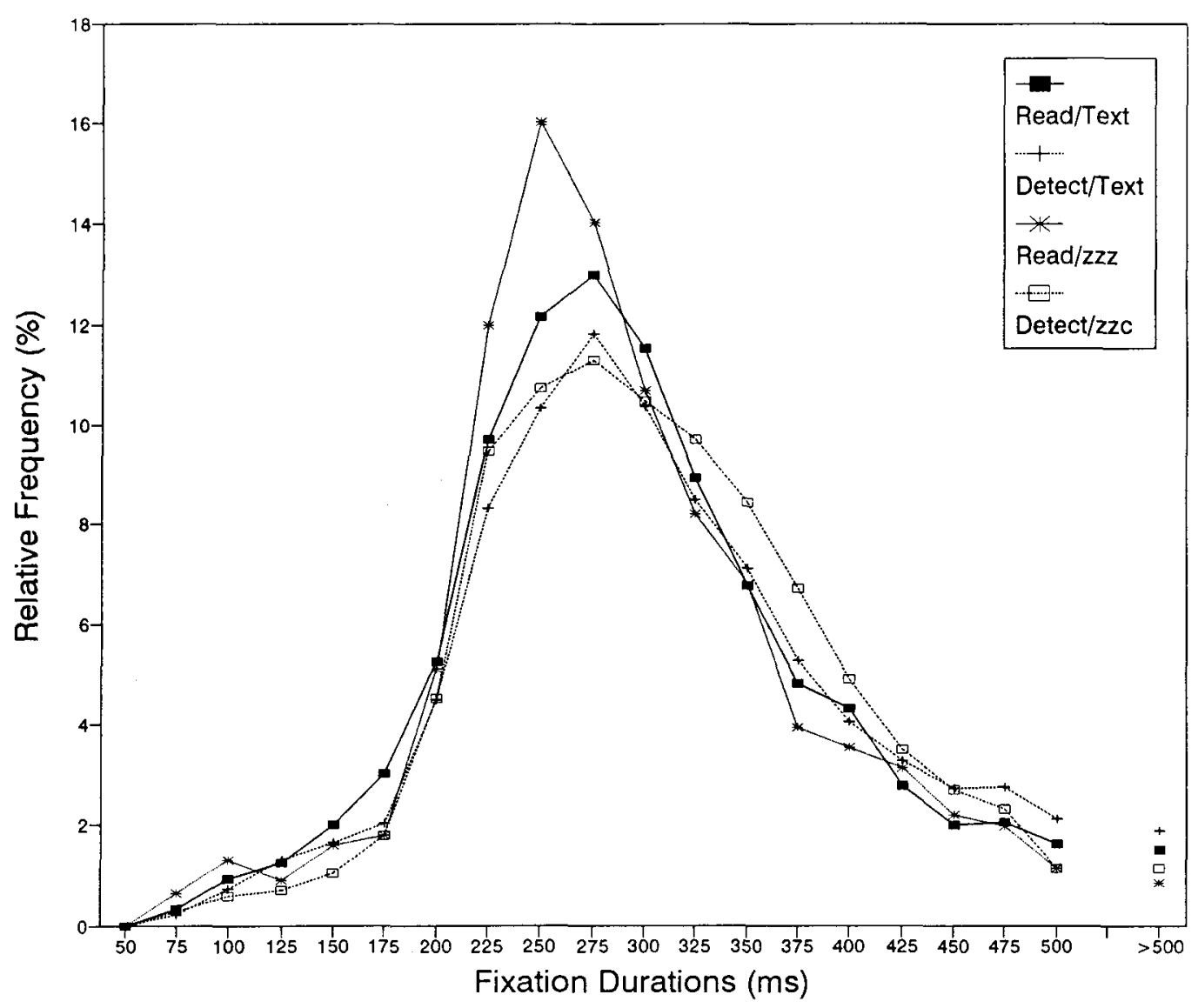

Figure 3. The distribution of fixation durations as a function of text type (standard text vs. $z$ text) and task type (reading vs. reading plus letter detection). Abscissa values show the lowest interval value; for example, the 50-msec value contains all fixations between 50 and $74 \mathrm{msec}$. 


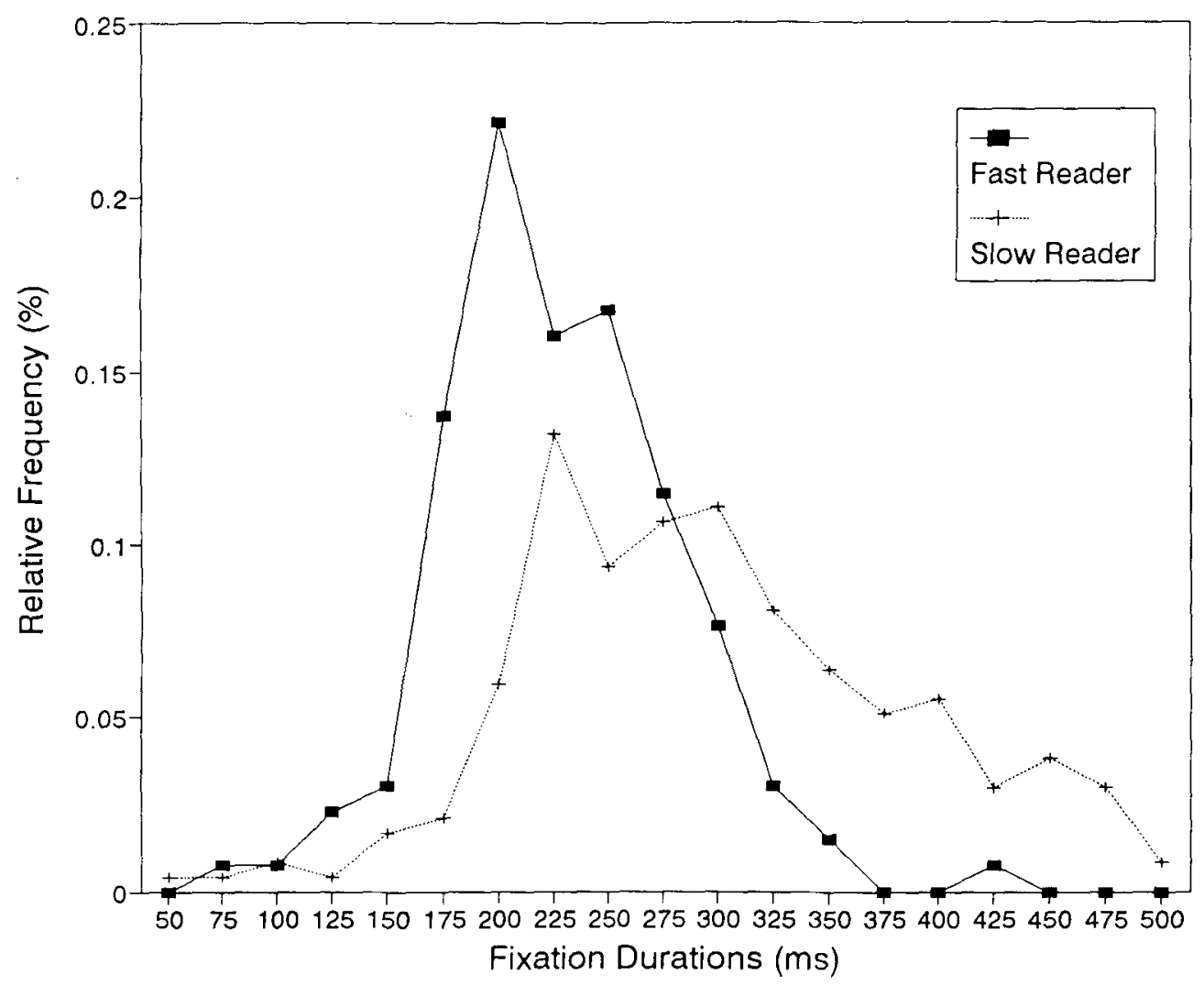

Figure 4. The distribution of fixation duration in the z-reading condition for the reader with the shortest and the reader with the longest mean fixation durations in this condition.

strings of letters are fixated. Following the procedure of Experiment 1, a separate regression analysis of z-text reading with the predictor saccade size and the criterion variable fixation duration was performed for each subject, and the resulting regression coefficients were subjected to a single-group $t$ test. The results revealed a significant positive effect of saccade size on fixation duration $[t(15)=$ 4.07, $S E=.03, p<.01$ ], indicating that visuospatial processes were applied to fixated letter strings, even when these strings were devoid of any linguistic information.

\section{GENERAL DISCUSSION}

Two experiments were conducted to examine the prevalence of brief fixations in reading conditions that were assumed to minimize the engagement of attention. In Experiment 1, text was read repeatedly, and in Experiment 2, subjects "read" $z$ text, which consisted of strings of letters that were devoid of linguistic meaning and required neither detailed perceptual nor linguistic analyses. The results showed that fixation durations decreased and that saccade size increased with repetition. Similarly, when homogeneous strings of $z$ text were read, fixation durations were shorter and saccades were larger than when normal text was read. These effects are consistent with prior studies that showed that variations in fixation durations and saccade size reflect on-line processing demands (see Rayner \& Pollatsek, 1989, for a review).

Text repetition and z-text reading may have resulted in a global decrease of fixation durations. If this were the case, then fixation duration distributions should show a shift toward shorter values. According to the attention hypothesis, however, global decreases in fixation duration could be the result of two distinct contributions. First, there may be a change in the proportion of mediumduration fixations between 150 and $300 \mathrm{msec}$, presumably at the expense of longer fixation durations. Second, there may be a distinct increase in the proportion of brief fixation durations, when the need to engage and disengage attention prior to and during fixations decreases substantially. This should lead to the emergence of a bimodal distribution, with one mode for brief (express) fixations and another mode for longer fixation durations.

In contrast to the predictions of the attention hypothesis, Experiment 1 did not yield a distinct distribution of brief fixations, even after text had been read repeatedly. Supplementary analyses revealed that repetition decreased demands of word-level analyses. Hence, the prevalence of brief fixations must be unrelated to attention-demanding linguistic analyses. The results of the z-text reading con- 


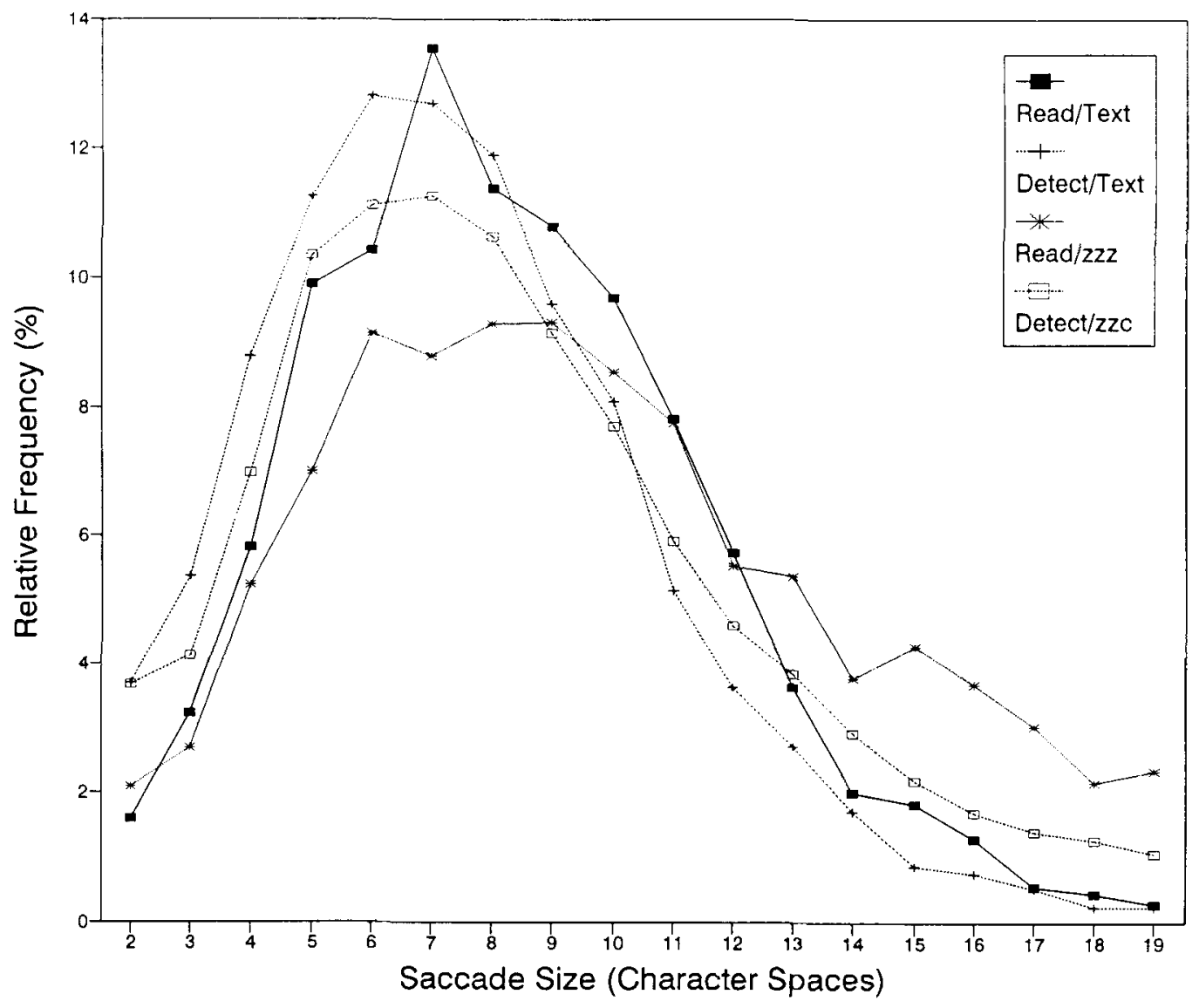

Figure 5. The distribution of saccade size in Experiment 2 as a function of text and task type.

dition of Experiment 2, which also failed to show a distinct distribution of express fixations, corroborates this conclusion. However, supplementary analyses of Experiment 1 and of the $z$-text reading condition of Experiment 2 also revealed effects of saccade size on the duration of the following fixation, presumably because saccade size affected the efficiency of visuospatial processes during the following fixation. Large saccades move the eyes to spatial locations that previously occupied low-acuity retinal locations, which may make the subsequent visuospatial processes more demanding.

Obligatory visuospatial processes thus may engage a type of attention that inhibits the occurrence of brief fixations, and linguistic analyses of text may engage a functionally distinct type of attention, which is unrelated to the occurrence of brief fixations. A more restrictive form of Fischer's (1993; Fischer \& Weber, 1993) attention hypothesis thus appears viable. According to this view, the occurrence of express saccades and brief fixations may be inhibited by attention-demanding visuospatial processes, not the engagement of attention in general.

However, rejection of the general form of the attention hypothesis has broader implications, as it challenges the necessity of attention as an explanatory construct in general. The execution of express saccades may be in- hibited whenever spatial analyses precede saccade specification, irrespective of whether attentional processes are implicated or not.

Other recent findings (Inhoff et al., 1992; Tam \& Stelmach, 1993) are also difficult to reconcile with Fischer's model of oculomotor control. In Tam and Stelmach's Experiment 5 , two types of gap conditions were created. Similar to standard gap trials, the fixated stimulus was extinguished prior to the lateral target presentation on some trials; similar to Braun and Breitmeyer's (1990) Experiment 3, an attended stimulus was extinguished prior to the lateral target presentation. However, in contrast to Braun and Breitmeyer's (1990) experiment, in which the locations of the attended and the target stimulus were completely correlated, the location of the attended stimulus did not predict target location. Attended stimuli were shown above or below fixation, and to-be-fixated targets were presented to the right or left of fixation. Under these conditions, no express saccades occurred when temporal gaps intervened between the offset of the attended stimulus above and below fixation and the presentation of the to-be-fixated lateral target.

Yet, some of the subjects in Tam and Stelmach's (1993) study executed express saccades when a gap intervened between the offset of the fixated stimulus and the onset 
of the lateral target, even when the fixated stimulus was not the target of subjects' attention. If mere presence of a fixation marker was sufficient to inhibit express saccades in purely oculomotor tasks, then it is unlikely that processes that control the execution of express saccades also control the occurrence of brief fixations in complex cognitive tasks such as reading, in which a visual signal is continuously visible during each fixation.

\section{REFERENCES}

BECKER, C. A. (1976). Allocation of attention during visual word recognition. Journal of Experimental Psychology: Human Perception \& Performance, 2, 556-566.

BoCH, R., \& Fischer, B. (1986). Further observations on the occurrence of express-saccades in the monkey. Experimental Brain Research, 63, 487-494.

Braun, D., \& Breitmeyer, B. G. (1988). Relationship between directed visual attention and saccadic reaction times. Experimental Brain Research, 73, 546-552.

Braun, D., \& Breitmeyer, B. G. (1990). Effects of reappearance of fixated and attended stimuli upon saccadic reaction time. Experimental Brain Research, 81, 318-324.

Fendrich, R., Hughes, H. C., \& Reuter-Lorenz, P. A. (1991). Fixation-point offsets reduce the latency of saccades to acoustic targets. Perception \& Psychophysics, 50, 383-387.

FisCHER, B. (1986). The role of attention in the preparation of visually guided eye movement in monkey and man. Psychological Research, 48, 251-258.

Fischer, B. (1987). The preparation of visually guided saccades. Reviews of Physiology, Biochemistry \& Pharmacology, 106, 1-35.

FisCHER, B. (1989). Visually guided eye and hand movements in man. Brain, Behavior \& Evolution, 33, 109-112.

Fischer, B. (1993). Saccadic reaction time: Implications for reading, dyslexia, and visual cognition. In $\mathrm{K}$. Rayner (Ed.), Eye movements and visual cognition: Scene perception and reading (pp. 31-45). New York: Springer-Verlag.

FisCHER, B., \& BREITMEYER, B. (1987). Mechanisms of visual attention revealed by saccadic eye movements. Neuropsychologia, 25, 73-78.

Fischer, B., \& WEBER, H. (1988). Significance of attentive fixation for the selection of saccade targets in different parts of the visual field in the rhesus monkey. Experimental Brain Research, 73, 577-582.

Fischer, B., \& Weber, H. (1990). Saccadic reaction times of dyslexic and age-matched normal subjects. Perception, 19, 805-818.

FISCHER, B., WEBER, H. (1993). Express saccades and visual attention. Behavioral \& Brain Sciences, 16, 553-567

HYONA, J., \& NIEMI, P. (1990). Eye movements during repeated reading of a text. Acta Psychologica, 73, 259-280.

INHOFF, A. W. (1984). Two stages of word processing during eye fixations in the reading of prose. Journal of Verbal Learning \& Verbal Behavior, 23, 612-624.

INHOFF, A. W., \& RAYNER, K. (1986). Parafoveal word processing during eye fixations in reading: Effects of word frequency. Perception \& Psychophysics, 40, 431-439.

INHOFF, A. W., TOPOLSKI, R., \& WANG, J. (1992). Saccade programming during short duration fixations: An examination of copytyping, letter detection, and reading. Acta Psychologica, 81, 1-21.

Just, M. A., \& Carpenter, P. A. (1980). A theory of reading: From eye fixations to comprehension. Psychological Review, 87, 329-354.

JUTNER, M., Wolf, W. (1992). Occurrence of human express saccades depends on stimulus uncertainty and stimulus sequence. $E x$ perimental Brain Research, 89, 678-681.

Kalesnykas, R., \& Hallett, P. E. (1987). The differentiation of visually guided and anticipatory saccades in gap and overlap paradigms. Experimental Brain Research, 68, 115-121.

KUCERA, H., \& FrANCIS, W. N. (1967). Computational analysis of present-day American English. Providence, RI: Brown University Press.
LORCH, R. F., \& MYERS, J. L. (1990). Regression analyses of repeated measures data in cognitive research. Journal of Experimental Psychology: Learning, Memory, \& Cognition, 16, 149-157.

Mayfrank, L., Mobashery, M., Kimming, H., \& Fischer, B. (1986) The role of fixation and visual attention in the occurrence of express saccades in man. European Archives of Psychiatry and Neurological Sciences, 235, 269-275.

McConkie, G. W., Underwood, N. R., Zola, D., \& Wolverton, G. S. (1985). Some temporal characteristics of processing during reading. Journal of Experimental Psychology: Human Perception \& Performance, 11, 168-186.

MORRISON, R. E. (1984). Manipulation of stimulus onset delay in reading: Evidence for parallel programming of saccades. Joumal of $E x$ perimental Psychology: Human Perception \& Performance, 10, 667-682.

O'ReGan, J. K. (1993). Optimal viewing position in words and the strategy-tactics theory of eye movements in reading. In K. Rayner (Ed.), Eye movements and visual cognition: Scene perception and reading (pp. 333-354). New York: Springer-Verlag.

Pollatsek, A., Rayner, K., \& Balota, D. A. (1986). Inferences about eye movement control from the perceptual span in reading. Perception \& Psychophysics, 40, 123-130.

RAYNER, K., \& DUFFY, S. A. (1986). Lexical complexity and fixation times in reading: Effects of word frequency, verb complexity, and lexical ambiguity. Memory \& Cognition, 14, 191-201.

RAYNer, K., \& POLLATSEK, A. (1989). The psychology of reading. Englewood Cliffs, NJ: Prentice-Hall.

Reuter-Lorenz, P. A., Hughes, H. C., \& Fendrich, R. (1991). The reduction of saccadic latency by prior offset of the fixation point: An analysis of the gap effect. Perception \& Psychophysics, 49, 167-175.

TAM, W. J., \& STELMACH, L. B. (1993). Viewing behavior: Ocular and attentional disengagement. Perception \& Psychophysics, 54, 211-222.

VITU, F. (1993). Prediction as an explanation for the occurrence of express saccades. (A commentary on Express saccades and visual attention). Behavioral \& Brain Sciences, 16, 592-593.

WEBER, H., \& Fischer, B. (1990). Effect of a local ibotenic acid lesion in the visual association area on the prelunate gyrus (area V4) on saccadic reaction times in trained rhesus monkeys. Experimental Brain Research, 81, 134-139.

\section{NOTES}

1. Most reading researchers use minimum fixation durations of 50 to $70 \mathrm{msec}$. Other researchers (e.g., Tam \& Stelmach, 1993) use minimum durations of $100 \mathrm{msec}$. Since express saccades range from 80 to $130 \mathrm{msec}$, the 50 -msec cutoff should not exclude any brief (express) fixations.

2. Two considerations led us to exclude fixations following onecharacter saccades. First, the software detected a one-character saccade whenever the eyes crossed a letter boundary, even when the corresponding saccade size was less than one character space. Small saccades within a letter remained undetected. The size of one-character saccades was thus ill-defined. However, Fischer and Weber (1993) reported a complete lack of express saccades for very small eye movements. Hence, our decision to eliminate fixations following "one-character space" saccades should not have affected the occurrence of brief (express) fixations.

3. Saccade duration increases with size and there may have been a slight increase in saccade durations across repetition. However, given the extremely short duration of saccades, ranging from 10 to $30 \mathrm{msec}$ during reading, any increment in passage reading time, due to increases in saccade duration, should be negligible.

4. We are grateful to Burkhard Fischer for suggesting Experiment 2 during the eye movement conference at the University of Massachusetts, 1991. According to Fischer's view, as expressed at the conference, the reading of homogeneous letter strings should minimize foveal and parafoveal attention engagement and yield express saccades.

(Manuscript received November 23, 1992; revision accepted for publication May 24, 1993.) 